\title{
Pigeons' short-term memories for surprising vs. expected reinforcement and nonreinforcement
}

\author{
WILLIAM S. MAKI \\ North Dakota State University, Fargo, North Dakota 58105
}

\begin{abstract}
Pigeons performed a delayed matching-to-sample task in which they matched red and green disks as comparison stimuli to samples of food and no food. The birds were also taught a discrimination between two lines: vertical $(S+)$ followed by food and horizontal $(S-)$ followed by no food. The two kinds of trials were then chained in infrequent probes such that (a) $\mathrm{S}+$ and $S-$ preceded samples of food and no food, (b) a longer than usual delay occurred, and then, (c) the comparison stimuli were presented. Therefore, in probes when $\mathrm{S}+$ preceded food and S- preceded no food, the samples were "expected." But in probes when S+ signaled no food and S- signaled food, the samples were "surprising." Matching to surprising samples was more accurate than matching to expected samples. This result completes a pattern of findings implying that surprising reinforcers enhance learning and also persist (are longer rehearsed) in short-term memory.
\end{abstract}

That an organism's expectancies may modulate learning in any given training situation has long been suspected (e.g., Tolman \& Brunswik, 1935) and the basic idea has since surfaced in a variety of theoretical treatments of animal learning (see Wagner, 1978). The present experiment aimed to provide support for a form of the expectancy view, which asserts that surprising events tend to persist in memory longer than do expected events. Following the lead of contemporary human memory theory (e.g., Atkinson \& Shiffrin, 1968), Wagner, Rudy, and Whitlow (1973) have assumed that the processing of a surprising US resembles the process known as "rehearsal." According to this view, rehearsal prolongs the residence of items in short-term memory (STM) and thereby fosters their eventual representation in longterm memory (LTM). Wagner et al. reasoned, therefore, that events during a posttrial interval should interfere with conditioning to the extent that those events compete for a limited rehearsal capacity. Wagner et al. provided rabbits with Pavlovian discrimination learning trials in which $\mathrm{CS}+$ signaled a US and $\mathrm{CS}-$ signaled no US. A third CS, $\mathrm{CS}_{3}$, was then paired with the US. The degree of responding to $\mathrm{CS}_{3}$ was used to assess the impact of posttrial events that were assumed to command varying degrees of rehearsal. When posttrial events were sur-

\footnotetext{
This research was partly supported by National Institute of Mental Health Grants RO3 MH 26534 and RO1 MH 31432. The results were summarized at the Midwestern Psychological Association meeting, Chicago, 1978. I thank G. Gillund, G. Hauge, W. Siders, and D. Shavalia for assistance with the experiment. Requests for reprints should be sent to W. S. Maki, Department of Psychology, North Dakota State University, Fargo, North Dakota 58105).
}

prising (CS + / no US or CS - /US), less conditioned responding to $\mathrm{CS}_{3}$ occurred than when posttrial events were expected (CS + /US or CS - /no US). Thus, it appeared that surprising posttrial events commanded rehearsal and so detracted from the processing that would otherwise have been devoted to representations of $\mathrm{CS}_{3}$-US pairings.

That surprising events might themselves be better rehearsed (and so, longer remembered) was more directly assessed by Terry and Wagner (1975). Rabbits were again provided with Pavlovian discrimination trials, CS + /US and CS - /no US. The subjects were separately taught a conditional discrimination. For example, when a US preceded a releasing stimulus $\left(C S_{R}\right)$, a US followed, but when no US served as the preparatory event and preceded $C S_{R}$, no US followed. The animals' responses to $\mathrm{CS}_{\mathrm{R}}$ thus became controlled by the presence or absence of a preceding US, and the degree of control depended on the time (retention interval) between the first US and $\mathrm{CS}_{R}$. Then the preparatory US was made expected or surprising by preceding it with one of the previously conditioned stimuli, $\mathrm{CS}+$ or $\mathrm{CS}-$, resulting in chained trials configured as $\mathrm{CS}+/ \mathrm{US} / \mathrm{CS}_{\mathrm{R}} / \mathrm{US}$ (expected) and $\mathrm{CS}-/ \mathrm{US} / \mathrm{CS}_{\mathrm{R}} / \mathrm{US}$ (surprising). The design was, in fact, more complicated that this, but the results supported the contention that surprising USs were better remembered than were expected USs.

Virtually all of the relevant research has employed aversive stimuli (electric shocks), so it might well be asked whether the data (and theory) are specific to that restricted set of stimuli. Blanchard and Honig (1976) provided some results which indicate that heightened processing of unexpected events might be a general feature of animal learning. Pigeons were provided noncontingent presentations of grain in the 
presence of one houselight $(\mathrm{S}+)$, but were not fed in the presence of another houselight $(\mathrm{S}-)$. Then a white keylight signaled food in the presence of $S+$ or $\mathrm{S}$ - for different groups of birds. The birds showed more autoshaped keypecking when food was surprising (presented in $\mathrm{S}-$ ) than when it was expected (presented in $\mathrm{S}+$ ).

In summary, then, the effectiveness of both appetitive (Blanchard \& Honig, 1976) and aversive (Kamin, 1969) reinforcers is enhanced if those reinforcing events are rendered surprising. Also, the memorability of an aversive event is improved if it is surprising (Terry \& Wagner, 1975). Conspicuously absent from this pattern is an analogous demonstration of better memory for surprising appetitive events. The present experiment, modeled after that of Terry and Wagner (1975), was designed to provide that demonstration. Pigeons were trained to perform delayed matching-to-sample (DMTS) in which their choices between two colored keys were controlled by prior occurrences of food or no food (Maki, Moe, \& Bierley, 1977). In other discrimination trials, food was signaled by one stimulus $(\mathrm{S}+)$ and no food was signaled by another stimulus $(\mathrm{S}-)$. DMTS and discrimination events were then occasionally chained in complex probe trials in which $\mathrm{S}+$ signaled samples of expected food or surprising no food and Ssignaled samples of surprising food or expected no food. By examining DMTS performances in these chained trials, it was possible to assess the degree of retention of surprising vs. expected occurrences of food and no food.

\section{METHOD}

\section{Subjects}

The subjects were one White Carneaux pigeon (Bird 1), three White King pigeons (Birds 17, 19, 22), and two Silver King pigeons (Birds 37, 38). The latter five birds were maintained at about $80 \%$ of their free-feeding weights on a diet of mixed grain received as reinforcement during experimental sessions and as home-cage maintenance rations after sessions; Bird 1 was maintained at $94 \%$. Water and grit were freely available at all times in the individual home cages. The experimental histories of the birds were lengthy and complex, but each bird had been trained to match to samples of food and no food in experiments just prior to the present one.

\section{Apparatus}

The birds worked in a Coulbourn Instruments modular environment. Three BRS/LVE pecking keys were arranged in a triangular display on the front panel. The center key $(20 \mathrm{~cm}$ above the floor) was located midway between the side keys $(16 \mathrm{~cm}$ apart and $19 \mathrm{~cm}$ above the floor). Each of the keys was backed by an inline projector. The center projector displayed a white disk, $2.54 \mathrm{~cm}$ in diameter, and vertical and horizontal white lines, each of which was $.64 \mathrm{~cm}$ wide and bisected an otherwise dark disk. The side keys displayed red and green disks. A BRS/LVE grain-feeder module was mounted beneath the center key. The chamber was placed inside of a larger, light-proof enclosure; sessions were therefore conducted in darkness, except for occasional illumination from the projectors and grain hopper. Extraneous sounds were masked by white noise presented through a speaker on the roof of the chamber and by noise from the exhaust fan mounted on the exterior wall of the outer enclosure. With both sources of noise on, the sound-pressure level was measured at $86 \mathrm{~dB}$ via a remote microphone suspended at a point $4 \mathrm{~cm}$ in front of the center key (re $20 \mu \mathrm{N} / \mathrm{m}^{2}$, as measured with a General Radio $1551-\mathrm{A}$ sound-level meter set on $C$ weighting).

The test chamber was interfaced to a laboratory computer (Automated Data Systems 1800E) located in another room. The computer was programmed to control stimulus events, record responses, and report data over an on-line teletypewriter. When multiple responses were recorded, the computer acknowledged new responses after minimum interresponse times of $.05 \mathrm{sec}$.

\section{Procedures}

During the many sessions of training and testing, baseline performances fluctuated in ways to be described below. Procedural alterations in response to these changes resulted in the development of slightly different procedures for each bird. Therefore, the common procedures will be first described, followed by details regarding each bird's training.

\section{General Procedures}

DMTS. By virtue of prior training, each subject was matching to samples of food and no food at the start of the experiment. Each session consisted of 72 trials. During each trial, after an intertrial interval of $20 \mathrm{sec}$, the center key displayed a white disk; a single peck darkened the key and produces a sample of food (2-sec access to grain) or no food ( $2 \mathrm{sec}$ darkness). Then, following a delay during which no stimuli were presented, the side keys were illuminated with the comparison stimuli (red and green disks). A peck on either key darkened both keys and initiated a 2 -sec period during which reinforcement (2-sec access to grain) could occur. A peck on the red side was reinforced following a sample of food, as was a peck on the green side following a sample of no food. In each of nine randomized blocks of eight trials, each of the four possible types of trials (sample of food or no food by correct choice on right or left side, and schematized in Table 1) occurred twice. Criterial DMTS performance was defined as $\mathbf{8 7 . 5 \%}$ or more correct (reinforced) comparison choices during trials beginning with food and during trials beginning with no food.

Because of their prior training, Birds 37 and 38 began the experiment showing criterial performances with delays of 12 and $6 \mathrm{sec}$, respectively. Birds 1, 17, 19, and 22 had not been trained for about 4 months so were provided four retraining sessions with 0 -sec delays. They then experienced $42-43$ sessions, during which delays were adjusted upwards until a delay was attained that barely, but consistently, supported criterial matching performances. The resulting delays for these four birds were 9,15 , 15 , and $11 \mathrm{sec}$, respectively.

Discrimination baseline. At this point, the number of DMTS trials/session was reduced to 36 by replacing one of each kind of trial in each block of trials with a discrimination learning trial. The latter trials also commenced with a white center key after the $20-\mathrm{sec}$ intertrial interval and are diagramed in Table 1. A single peck produced either the vertical $(\mathrm{S}+)$ or horizontal $(\mathrm{S}-)$ line, with each stimulus occurring twice per block. When $\mathrm{S}-$ was presented, the stimulus remained on the center key for $10 \mathrm{sec}$ and terminated in a 2-sec period of darkness (no food) independently of responding. When $\mathrm{S}+$ was presented, reinforcement was contingent on completion of a fixed-interval (FI) 10-sec schedule; i.e., the first peck after $10 \mathrm{sec}$ terminated $\mathrm{S}+$ and produced 2 -sec access to grain. Criterial performance was defined by discrimination ratio (DR) of at least .90 , signifying that at least $90 \%$ of all responses to $S+$ and $S$ - during a session occurred in the presence of $\mathbf{S}+$. All birds learned this discrimination rapidly, with stable performances manifested in 4-12 sessions.

Probe trials. Probe sessions were constructed like the discrimination baseline sessions, with the following exceptions. The 
Table 1

Representations of Delayed Matching, Discrimination Baseline, and Probe Trials

\begin{tabular}{|c|c|c|c|c|}
\hline \multirow[b]{2}{*}{ Trial } & \multicolumn{2}{|c|}{ Discrimination } & \multicolumn{2}{|c|}{ DMTS } \\
\hline & $\mathrm{s}^{\mathrm{D}}$ & Sample & Delay (sec) & Comparisons \\
\hline DMTS Baseline & & $\begin{array}{l}\text { Food } \\
\text { No Food }\end{array}$ & $\begin{array}{l}\mathrm{T} \\
\mathrm{T}\end{array}$ & $\begin{array}{l}\mathrm{R}+\mathrm{G}-\text { or } \mathrm{G}-\mathrm{R}+ \\
\mathrm{R}-\mathrm{G}+\text { or } \mathrm{G}+\mathrm{R}-\end{array}$ \\
\hline Discrimination Baseline & $\begin{array}{l}V(\text { FI 10) } \\
\text { H (EXT 10) }\end{array}$ & $\begin{array}{l}\text { Food } \\
\text { No Food }\end{array}$ & & \\
\hline Expected Probes & $\begin{array}{l}\text { V (FI 10) } \\
\text { H (EXT 10) }\end{array}$ & $\begin{array}{l}\text { Food } \\
\text { No Food }\end{array}$ & $\begin{array}{l}T+t \\
T+t\end{array}$ & $\begin{array}{l}\mathbf{R}+\mathrm{G}-\text { or } \mathbf{G}-\mathbf{R}+ \\
\mathbf{R}-\mathbf{G}+\text { or } \mathbf{G}+\mathbf{R}-\end{array}$ \\
\hline Surprising Probes & $\begin{array}{l}\text { H (EXT 10) } \\
\text { V (FI 10) }\end{array}$ & $\begin{array}{l}\text { Food } \\
\text { No Food }\end{array}$ & $\begin{array}{l}T+t \\
T+t\end{array}$ & $\begin{array}{l}\mathrm{R}+\mathrm{G}-\text { or } \mathrm{G}-\mathrm{R}+ \\
\mathrm{R}-\mathrm{G}+\text { or } \mathrm{G}+\mathrm{R}-\end{array}$ \\
\hline
\end{tabular}

Note-Each of the trials began with presentation of a white disk on the center key; a single peck initiated the first event of the trial. Other stimuli presented on the center key were a vertical $(V)$ line or a horizontal $(H)$ line. Stimuli presented as comparisons on the side keys were red $(R)$ and green $(G)$ disks with correct (reinforced) choice indicated by " + ."

number of blocks of trials was reduced from nine to eight so as to accommodate eight probe trials. Each probe session consisted of eight randomized blocks of nine trials, each block containing four DMTS trials, four discrimination trials, and one probe trial. The eight probe trials were randomly assigned to blocks. These trials began with a full discrimination trial (the white disk, $\mathrm{S}+$ or $\mathrm{S}-$, and reinforcement or nonreinforcement). Then, after the baseline delay of $\mathrm{T}$ sec incremented by $\mathrm{t} \mathrm{sec}$, comparison stimuli were presented, followed by reinforcement for correct choice. (The precise values of $T$ and $t$ are provided below under specific procedures.) Therefore, probe trials consisted of chained discrimination and DMTS trials in which the terminal event (food or no food) of the discrimination trial served as the initial event (the sample) of the DMTS trial. Each of the eight probe trials was uniquely defined by a combination of discriminative stimulus ( $\mathrm{S}+$ or $\mathrm{S}-$ ), subsequent sample (food or no food), and position of correct comparison stimulus (right or left side), as diagramed in Table 1. Operationally defined, then, when $S+$ preceded food or $S$ - preceded no food, the samples were expected by virtue of previous (and continuing) baseline training; when $\mathrm{S}+$ preceded no food and S - preceded food, the samples were surprising. During the surprising probes only, a sample of food was presented $10 \mathrm{sec}$ after the onset of S - independently of responding and no food was presented after the FI was completed during $S+$; otherwise, probe-trial procedures were the same as described earlier.

Generally, a probe session occurred every day (Test A). Later in the training of some birds, however, it became necessary to schedule probe sessions less frequently because of consistently depressed DRs. In this event, a probe session (Test B) occurred after the first discrimination baseline session in which the DR was at least .90 . The baseline delay values of $T$ sec and probetrial delay increments of $t \mathrm{sec}$ were adjusted upwards for individual birds when matching performances in all probe trials seemed to approach ceiling ( $100 \%$ correct), as next described, bird by bird. Finally, because data from single-probe sessions were limited (two trials for each combination of expectancy condition and type of sample), probe session data were pooled in blocks of four sessions and will be so treated for the remainder of the paper.

\section{Specific Procedures}

Bird 1. This subject performed well in baseline trials until the last day of the 11th block of probe sessions, in which the DR dropped below the .90 criterion. Then eight discrimination baseline sessions were conducted, after which the DR had reached criterion. In Blocks 12-14, accuracy during all kinds of probe trials rapidly improved, so during the next four sessions, the base delay ( $\mathrm{T} \mathrm{sec}$ ) was increased to $12 \mathrm{sec}$ at $1 \mathrm{sec} / \mathrm{day}$. For the same reason, the increments $(t)$ in probe delays were occasionally thereafter in- creased. During Blocks 1-17, $\mathrm{t}=2 \mathrm{sec}$; during Blocks 18-22, 23 , and $24-47, t=3,4$, and $5 \mathrm{sec}$, respectively. All testing was done with the Test A procedure.

Bird 17. DRs declined during Blocks 11 and 12 , so eight discrimination baseline sessions intervened between Blocks 11 and 12 and six more baseline sessions occurred after Block 12. During Blocks 13-25, the Test B procedure was followed, in which an average of 1.8 discrimination baseline sessions intervened between probe sessions. Throughout, $\mathrm{T}=15 \mathrm{sec}$ and $\mathrm{t}=2 \mathrm{sec}$.

Bird 19. The Test $A$ procedure with $T=15 \mathrm{sec}$ prevailed throughout. During Blocks 1-20, 21-23, and 24-50, $t=2,3$, and $4 \mathrm{sec}$, respectively.

Bird 22. Following 13 blocks of Test A probe sessions conducted at $\mathrm{T}=11 \mathrm{sec}$ and $\mathrm{t}=2 \mathrm{sec}$, four baseline sessions intervened in which $\mathrm{T}$ was increased to $12 \mathrm{sec}$. During the last days of Block 15, the DR dropped below .90 , so the remainder of testing was conducted with the Test B procedure. During Block 17, $t$ was increased from 2 to 3 to $4 \mathrm{sec}$, and Blocks 18-21 were conducted with $\mathrm{T}=12 \mathrm{sec}$ and $\mathrm{t}=4 \mathrm{sec}$. Before Block 22, four baseline sessions occurred in which $T$ was increased to 14 sec. Blocks $22-26$ were then conducted with $t=3 \mathrm{sec}$, and Blocks 27-32 with $\mathrm{t}=6 \mathrm{sec}$. During Blocks 16-32 (Test $\mathrm{B}$ procedure), the average number of discrimination baseline days intervening between probe sessions was 1.1 .

Bird 37. The Test A procedure was used in the first five blocks with $t=2 \sec$ (Blocks 1-2) and $t=3 \sec$ (Blocks 3-5). The DR declined in Block 5, so Blocks 6-13 were conducted with the Test B procedure (mean number of intervening baseline sessions $=2.7$ days), with $t=3 \mathrm{sec}$. Throughout all testing, $T=12 \mathrm{sec}$.

Bird 38. During all testing, $T=6 \mathrm{sec}$ and $t=2 \mathrm{sec}$. During the 16th block of the Test A procedure, the DR declined below .90 , so four sessions of discrimination baseline training followed. Blocks 17-24 were then conducted with the Test B procedure, with a mean of 1.1 discrimination baseline days intervening between probe sessions.

\section{RESULTS}

The data of most interest come from those sessions containing probe trials; these data are summarized in Table 2. Average percentage correct matching scores are presented separately for trials containing samples of food and no food within baseline, expected probe, and surprising probe trials. Also presented are mean DRs obtained from baseline, expected probe, and 
Table 2

Mean Percentage Correct Matching to Samples of Food and No Food and Mean Discrimination Ratios During Baseline, Expected Probe, and Surprising Probe Trials

\begin{tabular}{lccc} 
& & \multicolumn{2}{c}{ Probes } \\
\cline { 3 - 4 } Dependent Variable & Baseline & Expected & Surprising \\
\hline Percent Correct (Food) & 94 & 54 & 72 \\
Percent Correct (No Food) & 91 & 79 & 89 \\
Discrimination Ratio* & 95 & 94 & 96 \\
\hline
\end{tabular}

$*(\times 100)$

surprising probe trials. The data were first averaged across all probe sessions and then across birds to produce the displayed means. The individual baseline means for Birds $1,17,19,22,37$, and 38 were based on (respectively) 3,008, 1,600,3,200, 2,048, 832 , and 1,536 trials containing $S+$ (or samples of food) and the same number of trials containing $S-$ (or samples of no food). The corresponding numbers of expected (or surprising) probe trials were 376, $200,400,256,104$, and 192.

The data indicate that discrimination between $\mathrm{S}+$ and $\mathrm{S}-$ was highly accurate during all three kinds of trials. The mean DR during baseline trials did not significantly differ from the mean DR obtained during expected or surprising probe trials $[F(1,5)=1.11$, and $F<1$, respectively]. Thus, during both kinds of probe trials, the birds behaved in a manner consistent with baseline training, and it may therefore be surmised that the birds expected food given $\mathrm{S}+$ and no food given $\mathrm{S}$ - during surprising probe trials.

Next, consider the effects of increasing probe-trial delays $(T+t \mathrm{sec})$ over the usual baseline delay $(T \mathrm{sec})$. Accuracy of matching to samples of food in both expected and surprising probe trials was significantly less than the accuracy of matching to samples of food in baseline trials $[\mathrm{Fs}(1,5)=46.77, \mathrm{p}<.01$, and 62.50 , $p<.001$, respectively]. For matching to samples of no food, accuracy during expected probes was less than in baseline trials $[\mathrm{F}(1,5)=8.63, \mathrm{p}<.05]$ but accuracy during surprising probes and baseline trials differed little $(F<1)$. So, for the most part, the increased delays during probe trials was effective in reducing matching accuracy below the ceiling levels maintained under baseline conditions.

Having established that (a) the animals behaved as if they expected samples of food and no food when signaled by $\mathrm{S}+$ and $\mathrm{S}-$, and (b) matching performance was depressed (the samples were forgotten) during expected probes, we may then ask whether surprising samples were better remembered than expected samples. That this was, in fact, the case was confirmed by an analysis of variance performed on matching accuracy during probe trials: Accuracy was significantly better during surprising probes than during expected probes $[F(1,5)=25.43, p<.01]$, with all six birds showing the effect. Moreover, this result held for both samples of food $[\mathrm{t}(5)=2.65$, $p<.05]$ and samples of no food $[t(5)=2.88$, $\mathrm{p}<.05]$. The analysis also revealed that matching to samples of food during probes was significantly inferior to matching to samples of no food $[F(1,5)$ $=27.54, p<.01]$, all six subjects showing the effect. The interaction between these factors, however, was not significant $(\mathrm{F}<1)$.

Table 3 presents percentage correct matching to expected and surprising samples separately for each bird. These data are averaged over probe sessions and over food and no-food trials. Different averages are presented for the Test $A$ procedure (when probe trials occurred each day), the Test B procedure (when probe trials only occurred after a criterial baseline session), and for both procedures combined. Examination of the combined scores suggests that the magnitude of the surprise effect varied between subjects. Consequently, analyses of variance were performed on the individual subject's data, using interactions with blocks of sessions as error terms. The differences between combined "expected" and "surprising" scores were significant for Birds 1, 17, 19, and 38 $[F(1,46)=59.21, p<.001 ; F(1,24)=23.26$, $\mathrm{p}<.001 ; \mathrm{F}(1,49)=65.54, \mathrm{p}<.001 ;$ and $\mathrm{F}(1,23)$ $=12.37, \mathrm{p}<.01$, respectively]. The difference for Bird 22 was marginally significant $[F(1,31)=4.12$, $\mathrm{p}<.10]$ and the difference for Bird 37 was not significant $[F(1,12)=2.68]$. Nevertheless, the latter

Table 3

Percentage Correct Matching to Expected and Surprising Samples During Tests A and B Presented for Individual Subjects

\begin{tabular}{|c|c|c|c|c|c|c|}
\hline \multirow[b]{2}{*}{ Bird } & \multicolumn{2}{|c|}{ Test A } & \multicolumn{2}{|c|}{ Test B } & \multicolumn{2}{|c|}{ Combined } \\
\hline & Expected & Surprising & Expected & Surprising & Expected & Surprising \\
\hline $\begin{array}{r}1 \\
17 \\
19\end{array}$ & $\begin{array}{l}69 \\
61 \\
68\end{array}$ & $\begin{array}{l}88 \\
68 \\
85\end{array}$ & 52 & 90 & $\begin{array}{l}69 \\
57 \\
68\end{array}$ & $\begin{array}{l}88 \\
79 \\
85\end{array}$ \\
\hline $\begin{array}{l}22 \\
37 \\
38\end{array}$ & $\begin{array}{l}77 \\
75 \\
61\end{array}$ & $\begin{array}{l}78 \\
75 \\
71\end{array}$ & $\begin{array}{l}72 \\
68 \\
55\end{array}$ & $\begin{array}{l}80 \\
80 \\
82\end{array}$ & $\begin{array}{l}74 \\
71 \\
59\end{array}$ & $\begin{array}{l}79 \\
78 \\
75\end{array}$ \\
\hline
\end{tabular}


two birds showed extended periods of time during which the superiority of surprising samples was evident, particularly during the Test $B$ procedure.

Separate analyses performed on data obtained in Tests A and B revealed the following results. Three of the birds that were eventually switched to the Test B procedure showed small effects (Birds 17 and 22) or no effect (Bird 37) of the surprise manipulation during Test $\mathrm{A}$ (all three Fs $<1$ ). All three birds, however, showed substantial effects in Test B $[\mathrm{F}(1,12)$ $=148.01, \mathrm{p}<.001 ; \mathrm{F}(1,16)=6.03, \mathrm{p}<.05$; and $\mathrm{F}(1,7)=6.22, \mathrm{p}<.05$, respectively]. This pattern of results should not be taken to mean that the surprise effect is specific to the Test $B$ procedure. Recall that two other birds ( 1 and 19) only experienced the Test $\mathrm{A}$ procedure, and note that Bird 38 showed reliable differences in both Test $\mathrm{A}$ and Test $\mathrm{B}$ $[F(1,15)=5.05, \mathrm{p}<.05 ;$ and $\mathrm{F}(1,7)=8.65, \mathrm{p}<.05$, respectively].

Further analysis of the data revealed that the surprise effect was not immediately present but, rather, developed over the first few blocks of sessions containing probe trials. DMTS performance resulting from surprising and expected probe trials was examined for the first (1-5) and second (6-10) five blocks of probe-trial sessions. The analysis of variance included probe (expected vs. surprising), sample (food vs. no food), and training (first vs. second five blocks). The mean accuracies obtained in the analysis are presented in Table 4 . The surprise effect grew as a function of stage of training as indicated by the significant Probe by Training interaction $[F(1,5)$ $=9.98, \mathrm{p}<.05]$; the size of the interaction, however, did not depend on the type of sample $[F(1,5)=1.23]$. Analyses of simple main effects revealed that during the first five blocks, the mean accuracies during expected $(68 \%)$ and surprising $(70 \%)$ probe trials did not significantly differ $(F<1)$. During the second five blocks, DMTS accuracy during surprising probe trials $(79 \%)$ significantly exceeded that during expected probes $(63 \%)[F(1,5)=18.92, p<.01]$. The increase in matching accuracy during surprise

Table 4

\begin{tabular}{|c|c|c|c|c|}
\hline \multicolumn{5}{|c|}{$\begin{array}{c}\text { Mean Percentage Correct Matching to Samples of Food and } \\
\text { No Food During Expected and Surprising Probe Trials } \\
\text { as a Function of Probe Trial Experience }\end{array}$} \\
\hline \multirow[b]{3}{*}{ Sample } & \multicolumn{2}{|c|}{ Expected } & \multicolumn{2}{|c|}{ Surprising } \\
\hline & \multicolumn{4}{|c|}{ Blocks } \\
\hline & $1-5$ & $6-10$ & $1-5$ & $6-10$ \\
\hline $\begin{array}{l}\text { Food } \\
\text { No Food }\end{array}$ & $\begin{array}{l}58 \\
79\end{array}$ & $\begin{array}{l}53 \\
73\end{array}$ & $\begin{array}{l}59 \\
82\end{array}$ & $\begin{array}{l}72 \\
86\end{array}$ \\
\hline
\end{tabular}

Note-Data were averaged over blocks of probe trial sessions; the number of trials contributing to each mean was 40 per subject. probes over blocks was significant $[F(1,5)=25.00$, $\mathrm{p}<.0 \mathrm{i} \mathrm{i}$, but the smaller decline in accuracy during expected probes was not $[F(1,5)=3.09]$.

\section{DISCUSSION}

The present experiment demonstrated a "surprise effect" in DMTS, both in the group and the intrasubject data; pigeons more accurately matched to surprising than to expected samples of food and no food after long delays. Thus, like aversive events (Terry \& Wagner, 1975), appetitive events seem better remembered if surprising than if expected. Moreover, the present results extend the surprise effect to the unexpected omission of reinforcers (USs) as well as the unexpected occurrence of such events (cf. Terry \& Wagner, 1975).

Wagner's (1978) information-processing model of Pavlovian conditioning accounts for the major finding reported here, just as it does the parallel surprise effect in Pavlovian conditioning (Terry \& Wagner, 1975). The model assumes that stimulus events receive processing (rehearsal) to the extent that such items are not already resident in STM. The present findings would then be explained as follows. Upon presentation of $\mathrm{S}+$, a representation of its associate (food) was retrieved from LTM, thus "priming" STM. When the anticipated event then occurred, its representation was already in STM, and so the occurrence of the event itself was less well rehearsed (and so forgotten faster). In contrast, when $\mathrm{S}$ - preceded food, no such representation was placed in STM prior to the occurrence of food itself and so the sample of food was rehearsed. Extension to the case of no food as the to-be-remembered event is straightforward. When $\mathrm{S}$ - preceded no food, the absence of food was prerepresented in STM and so not later rehearsed to the same degree as when $\mathrm{S}+$ preceded no food.

Wagner's priming model affords an attractive theoretical view of the surprise effect reported here, particularly because it simultaneously accounts so well for a large variety of conditioning and habituation phenomena (e.g., Pfautz \& Wagner, 1976). But some results of the present study may prove difficult to accommodate. For one, the superior retention of surprising samples of food and no food developed as a function of experience with probe trials. It is not clear how the priming model can cope with this observation, short of invoking auxiliary mechanisms.

Another problem is presented by the way in which the subjects reacted to occurrences of $\mathrm{S}+$ alone (i.e., surprising omissions). In the present study, omissions of food following $\mathrm{S}+$ were better remembered than omissions of food following $\mathrm{S}-$. As outlined above, the priming model could be made to handle such an 
outcome. However, Terry and Wagner (1975) reported data from an analogous set of trials which seem to conflict with the present findings. On some trials, their rabbits received $\mathrm{CS}+$ or $\mathrm{CS}-$ alone (no US), followed after a delay by $\mathrm{CS}_{\mathrm{R}}-\mathrm{US}$. More responding was noted to $C S_{R}$ after the preparatory $\mathrm{CS}+$ than after $\mathrm{CS}-$; that is, the rabbits did not behave as if a CS + alone episode was equivalent to the surprising omission of the US. (Recall that the omission of the preparatory US was for these subjects the conditional cue, indicating that the US subsequently would not be paired with $\mathrm{CS}_{R}$.) The reason for this discrepancy is not clear, but if species differences can be safely ruled out (see Maki et al., 1977), then some aspect of the procedural differences may become important. For example, in the present experiment, the appropriate (reinforced) behavior toward comparison stimuli (analogous to $\mathrm{CS}_{\mathrm{R}}$ ) was governed by the prior sample of food or no food, even in probe trials. In Terry and Wagner's experiment, $\mathrm{CS}_{\mathrm{R}}$ and US were paired in all probe trials (for the illustrative group of subjects discussed here). What effect that practice might have had on performance during test trials cannot now be easily determined, so detailed explanations seem premature.

The present findings, including those relating to the effects of experience with probe trials and matching to surprising omissions of food, are compatible with another possibility. In agreement with the priming model, the hypothesis considered here claims that expected samples were not as well rehearsed as surprising samples. The present hypothesis, however, suggests that processing of expected samples was less effective because the comparison stimuli were not expected following the discrimination trial configurations that began probe trials. The majority of $\mathrm{S}+/$ food and $\mathrm{S}-/$ no-food sequences were baseline discrimination trials, which therefore were not followed by presentation of comparison stimuli. This hypothesis may account for the generally poorer DMTS performance during probe trials which cannot unambiguously be attributed to increased delays. The events signaling samples of food were also different in probe trials, resembling discrimination baseline trials more closely than DMTS baseline trials. Some of the overall DMTS loss might therefore have resulted from the birds failing to differentiate probe from baseline discrimination trials. So it may be that the birds did not rehearse occurrences of food and no food in expected probe trials because such processing was normally not reinforced by the occurrence of comparison stimuli following trials begining with $\mathrm{S}+$ or $\mathrm{S}-$. On this account, the birds might have learned to rehearse on probe trials when comparison stimuli were predicted by the surprising sequences, $\mathrm{S}+/$ no food and $S-/$ food.
It should be noted that the foregoing suggestion may also be compatible with the other features of the data reported by Terry and Wagner (1975). In that Pavlovian analogue of the present experiment, two tests were administered. Judging from Terry and Wagner's Figures 5 and 6 , in the case of $\mathrm{CS}+/ \mathrm{US} /$ $\mathrm{CS}_{\mathrm{R}} / \mathrm{US}$ and $\mathrm{CS}-/ \mathrm{US} / \mathrm{CS}_{\mathrm{R}} / \mathrm{US}$ sequences, it appears that their surprise effect at long delays also increased (approximately doubled) over repeated tests containing their equivalent of probe trials (though this comparison is not entirely appropriate, because "long" delays of different lengths were used in their two tests). Moreover, at least in their Test II, the surprise effect was apparent at long $(8-\mathrm{sec})$ but not at short $(2-\mathrm{sec})$ retention intervals. The absence of the surprise effect at short delays was initially (and perhaps accurately) interpreted by those authors as resulting from a ceiling effect. In the present context, it could be viewed in a different manner. If rehearsal of representations of reinforcers (USs) serves to prevent their decay from STM, one might anticipate little forgetting at short delays, and so little effect of manipulations that alter rehearsal of newly represented items in STM. Terry and Wagner also reported a correlation across subjects between the differential responding maintained by $\mathrm{CS}+$ and CS - with the magnitude of the surprise effect. Such a relationship certainly follows from the priming model (the greater the expectancy, the greater the priming). But the correlation does not follow from the present hypothesis in any simple, direct way. It would be necessary to assume that those animals that showed the most CS + vs. CS - discrimination were also those animals that least expected retention tests. Thus, with some qualifications (albeit highly speculative ones), these aspects of Terry and Wagner's results can be seen as congruent with the hypothesis proposed here; at the very least, they do not seem entirely inconsistent with it.

In summary, a surprise effect was found in pigeons' delayed matching to samples of food and no food; surprising samples maintained more accurate matching than did expected samples. That the effect developed with testing experience does not seem to follow from Wagner's (1978) priming model of expectancy effects in animal learning and memory. It is, however, consistent with the hypothesis that animals can learn when to rehearse and also when not to rehearse information in STM. To the reader familiar with the work on "directed forgetting" in human memory (e.g., Bjork, 1972), this hypothesis will not appear unreasonable. It should be recognized, though, that neither hypothesis appears to cleanly account for all the data, and the present data on matching to surprising omissions of reinforcers do not agree with earlier data on conditional Pavlovian reactions to signaled 
US omissions (cf. Terry \& Wagner, 1975). Consequently, the resolution of the issue raised here must rest on additional empirical developments.

\section{REFERENCES}

Atkinson, R. C., \& Shiffrin, R. M. Human memory: A proposed system and its control processes. In K. W. Spence \& J. T. Spence (Eds.), The psychology of learning and motivation: Advances in research and theory (Vol. 2). New York: Academic Press, 1968.

BJork, R. A. Theoretical implications of directed forgetting. In A. W. Melton \& E. Martin (Eds.), Coding processes in human memory. Washington: Winston, 1972.

Blanchard, R., \& Honig, W. K. Surprise value of food determines its effectiveness as a reinforcer. Journal of Experimental Psychology: Animal Behavior Processes, 1976, 2, 67-74.

Kamin, L. J. Selective association and conditioning. In N. J. Mackintosh \& W. K. Honig (Eds.), Fundamental issues in associative learning. Halifax: Dalhousie University Press, 1969.

MAKI, W. S., JR., MOE, J., \& BIERLEY, C. Short-term memory for stimuli, responses, and reinforcers. Journal of Experimental Psychology: Animal Behavior Processes, 1977, 3, 156.177.

Pfautz, P. L., \& Wagner, A. R. Transient variations in responding to Pavlovian conditioned stimuli have implications for the mechanism of "priming." Animal Learning \& Behavior, 1976, 4, 107-112.

TERRY, W. S., \& WAGNER, A. R. Short-term memory for "surprising" versus "expected" unconditioned stimuli in Pavlovian conditioning. Journal of Experimental Psychology: Animal Behavior Processes, 1975, 1, 122-133.

Tolman, E. C., \& BRunswik, E. The organism and the causal texture of the environment. Psychological Review, 1935, 42, 43-77.

WAGNer, A. R. Expectancies and the priming of STM. In S. H. Hulse, H. Fowler, \& W. K. Honig (Eds.), Cognitive processes in animal behavior. Hillsdale, N.J: Erlbaum, 1978.

W AGNER, A. R., Rudy, J. W., \& WhrtLow, J. W. Rehearsal in animal conditioning. Journal of Experimental Psychology, 1973, 97, 407-426.

(Received for publication June 8, 1978; revision accepted July 31,1978 .) 